\title{
What clothes should Leisure Research wear?
}

\author{
Steven Miles \\ Department of Sociology, Manchester Metropolitan University, Eleanor Rathbone Building, \\ Rosamond Street West, Manchester M15 6LL.
}

The relationship between leisure and consumption, the broader context within which the relationship between leisure and dress must be understood, did not really become a serious topic of social scientific investigation until the late twentieth century. It was at that point that the realization was made that what people consumed was as worthy of critical interrogation as what they produced. Since that time, the world of consumption has endured at least at the fringes of debates in a number of disciplines, including sociology, history, human geography, and cultural studies. Such subjects recognized that the meanings people attached to what they consume, and specifically how they dress, far from being trivial, could tell us much about the changing conditions of the world in which we lived. Most importantly consumption came to be recognized as an ideological entity, it had effectively become naturalized in the construction of our everyday lives to the extent that its fascination actually lay in its apparent triviality. Consumers did not necessarily think about what they consumed as anything more than a perfectly 'normal' state of affairs. This itself was testament to its very significance. As Fiske $(1989,14)$ puts it in his discussion of jeans, 'by wearing jeans we adopt the positions of subjects within.... [an] ideology, become complicit with it and therefore give it a material expression; we "live" capitalism through its commodities, and, by living it, we validate and invigorate it.' The contention that consumption is ideological is perhaps non-contestable. What is worthy of more immediate consideration is that the nature of this ideology is further complicated in what has allegedly become an age of prosumption: an era in which the boundary between production and consumption is so much more blurred than it was in the past. Furthermore, the argument I will present here is that such a shift has particularly significant implications for the evolution of leisure research as a critical discipline.

In 1990, when debates around post-modernism were all the rage, Alex Callinicos argued that the world that we were coming to experience at that time was not fundamentally different from the capitalist mode of production that had dominated for two centuries previously. In fact, he argued, the debate over post-modernism told us more about the tenuous state of the intelligentsia and its political disillusionment than it did about social and economic change itself. From this point of view, the late twentieth century saw a pronounced shift in the nature of intellectual endeavor: in an apparently ever-changing world, which appears to be dominated by the superficial appeals of consumerism, intellectuals are apparently left unsure of their place in the world. Post-modernism thus offered a means of expressing a deep disillusionment with a state of affairs in which the Left could no longer make a difference. For many social scientists, this represented, albeit perhaps sub-consciously, a profound declaration of defeat. I want to argue here that the above process remains alive and well through the demise of a leisure research that continues to struggle to establish its own disciplinary identity under such conditions.

The arena of leisure emerged as a result of a set of social and cultural circumstances that played themselves out through a weakening of structures and divisions that had previously held sway. But as Roberts (2006) points out, leisure was itself as unstable as the world it was emerging in. Such instability was intensified by the process of commodification. What we buy, and specifically what we wear, filled a gap, providing a sense of stability in an otherwise unstable world. But this did not happen overnight. Several of the authors in this special issue 
refer to the work of Veblen (1925/1899) as perhaps the first scholar to address critically the relationship between leisure and consumption and specifically on how to adorn ourselves for particular purposes. As Veblen puts it, 'In order to gain and to hold the esteem of men it is not sufficient merely to possess wealth or power. The wealth or power must be put in evidence, for esteem is only awarded in evidence' (p. 24). What we wear tells us much, then, about how we see ourselves, but it also provides a means of understanding how it is the world sees us.

Since the above ideological transition took root the assumption might be that leisure studies has endeavored to take on the full significance of the world of consumption. Authors such as Rojek (1993) have indeed directly addressed the extent to which consumer culture elicits false consciousness in consumers who live in a world in which possessions become conflated with 'being' and in which competition between individuals becomes the normal state of affairs. For Rojek, in a consumer society, leisure provides nothing more than an illusory freedom that persuades us that we are able to enact freedom of choice over our lives. But the effect of consumption on our lives is a sophisticated one. Indeed, the tentacles of commodified leisure have stretched so far that it is often difficult to identify where production starts and consumption begins. So, effectively, spaces of production have been transformed into spaces for consumption, as demonstrated, for example, by Johnson's (2013) discussion of farmers' markets and their ability to reassert what are effectively middle class consumer values and ideals. Online communities have also been especially influential in asserting a consumer ethic. The process of prosumption-how it is that contemporary forms of consumption, and not least those carried out online - transcend the boundary between production and consumption so that the consumer actively works (e.g. by collaborating with fellow gamers or by playing a part or character in some form of experiential consumption) in order to achieve the escape that he or she aspires to, has significant consequences for how we understand the experience of leisure.

As Ritzer and Jurgenson (2010) note, in prosumer capitalism, control and exploitation take on a different character than in the other forms of capitalism. There is a trend towards unpaid rather than paid labor (e.g. eBay) and towards offering products at no apparent cost, and the system is marked by a new abundance where scarcity once predominated. We can reflect here upon the increasingly significant role of the digital in the world of leisure. In this context, Woermann (2011) argues that prosumption is more than about the extension of productive capacity to consumers. Rather, it is about the growing valorization of creativity as displayed through formative practices of consumption. Woermann looks at this development in the context of lifestyle sports and in particular Freestyle skiing and in doing so draws attention to the specific kinds of clothing that such sports imply and the implications these forms of dress have for subcultural identities. At the heart of this lies the question of authenticity, the degree to which those involved in Freestyle skiiing can, for example, dress 'authentically' in a context that is so driven by measures of appropriate consumption. For Woermann, prosumption can be seen as a functional equivalent to, rather than an antagonist of, commodity consumption in that both provide complementary ways of reproducing subcultural meaning. Thus, he describes how members of the Freestyle skiing subculture might knit their own beanies, redesign equipment by spray-painting them, construct their own obstacles in the backyard, or perhaps organize their own semi-professional events. Freeskiing is thus about more than participating in the sport (see Crockett's article in the first part of this Special Issue). It is about engaging in the broader cultural context in which the sport operates. Members of the Freestyle skiing "scene" see themselves not only as consumers of that scene but as active producers of it, 'Through a range of scene-specific practices, 
prosumption is deeply enmeshed into the cultural landscape of the Freestyle skiing community: At the core of the Freestylers' aspirations lies - in their own understanding - the desire to express their own style by, for example, developing their own way of doing a certain trick, creating a personal look in clothing or designing their own website in a certain manner. The degree of freedom that defines Free-skiing in the understanding of its members is not just a freedom to choose... but a freedom to create something that can be said to be unique' (Woermann 2011, 627).

The degree of freedom that prosumption allows is clearly a matter for considerable debate. Millington (2016) for example, discusses the elevation in recent years of a fitness boom defined by the emergence of fitness apparel and equipment at a time when fitness was effectively re-imagined as a moral responsibility. This technologically-driven boom emphasizes human-technology interactivity and a broadened version of consumption in which individual users participate in online communities. Millington contemplates the emergence of an "automated prosumption", a process manifested through the consumption of, for example, wearable tracking devices, smart garments embedded with sensor technology, and fitness application software and mobile apps. At one level at least, this shift can be seen to constitute a re-invention of the meaning of fitness as an interactive process and as such involves a much less passive experience where technology responds to the consumer and the consumer to technology. For Millington, fitness has become "customizable" insofar as it is apparently all about constructing a programme of fitness around your own personal needs. Such customization broadens the fitness market and stretches its longevity: a personalized program of fitness is potentially a never-ending project. Even so, the new fitness experience is much more likely to be networked so that these experiences can be shared with consumers experiencing similar 'journeys'. The new fitness experience offers the opportunity for consumers to be an active part of a fitness community. But this experience, of course, remains highly commodified, a version of commodification in which the individual is increasingly watched or surveilled. In effect, then, fitness is no longer simply a field for shaping the self; it has become a matter of simultaneous production and consumption and as such it is both liberating and constraining at one and the same time: 'The fitness participant is scrutinized more intensely and by more actants than ever before. Charles Atlas, in the interwar years, and Jane Fonda, in the first fitness boom, could only implore and direct their consuming audiences through media. The new purveyors of fitness know no such restraints' (Millington 2016, 22 -23).

So what does all of this add up to? The process of prosumption necessitates nothing less than a re-evaluation of what it is we mean by leisure. Such a contention is, of course, no more highlighted than in the case of the rise of social media such as Facebook, Twitter, YouTube, Weibo, and LinkedIn. Fuchs (2013) thus describes the blurring of labor and leisure time as the so-called emergence of "playbour", not least within the realms of gaming consumption (see also Googin, 2011). In turn, Kücklich (2005) highlights a process in which work has been deregulated so that the primary source of coercion is no longer institutionally driven, but through the individual him or herself. This change amounts to a new regime of self-discipline that allows us to describe new forms of labor that are now better understood as play and freedom. As such, rules feel liberating. By committing to them, the solitary gamer is the archetype of the individual who receives maximum pleasure by submitting unreservedly to the rules laid down for them. Such a process is indeed often reversed in the workplace where it is increasingly common for management to introduce dimensions of fun, play, and leisure (symbolized perhaps by the ubiquity of the table tennis in 'modern' workplaces), to maximize productivity, loyalty, and work satisfaction. 


\section{Conclusions}

The word "leisure" is apparently harmless, almost neutral in its intent and certainly in its effect. Indeed, in the papers presented in both parts of this special issue, consumption is often assumed to be a space of enactment, fulfilment, and identity construction. For this reason, research into leisure can often feel rather descriptive in nature. But the point here is that in a world of prosumption leisure spaces are simply not neutral. If I may return briefly to the world of fitness, Frew and McGullivary (2005) suggest that the gym is a factory of fear; it provides a space in which consumers believe in the sovereignty that consumption can provide, whilst avoiding any conception of the mechanisms that underpin it. Leisure convinces us that it can provide us with the arenas we need to escape the monotony and the constraints of everyday life. Prosumption gives the consumer control, but that control comes at a cost. The challenge for leisure research lies in understanding what that cost might be. Back in 1991, Susan Willis argued that the consumption of fitness, on the part of women specifically, is liberating insofar as it involves the propagation of the image of women as independent, self-assured and powerful individuals. But in this context, dress is as constraining as it is enabling. For Willis, the workout is a highly evolved commodity form which obliges women to define themselves through the adornment of their bodies. This tension accentuates prosumption and as such is worthy of particular attention by leisure researchers. Prosumption offers leisure research a means of re-framing the leisure experience as pro-active, yet ideological in nature. By doing so, it may be the case that the leisure research of the future can aspire to a promised land which is less about the insecurities of a group of scholars unsure of their own place in the world and more about standing up to and challenging the increasingly difficult pressures that a consumer society puts in front of it.

\section{References}

Callinicos, A. 1990. Against Postmodernism: A Marxist Critique. Cambridge: Polity. Fiske, J. 1989. Understanding Popular Culture. London: HarperCollins.

Frew, M. and McGullivary, D. 2005. "Health clubs and body politics: aesthetics and the quest for physical capital.” Leisure Studies. 24 (2): 161-175.

Fuchs, C. 2013. "Digital prosumption labour on social media in the context of the capitalist regime of time." Time \& Society. 23 (1): $97-123$.

Googin, J. 2011. "Playbour, farming and leisure: work, play and boredom." Ephemera: Theory and Politics in Organizations. 11 (4):357 -368.

Johnson, A. J. 2013 'It's more than a shopping trip': leisure and consumption in a farmers' market." Annals of Leisure Research. 16 (4): 315 - 331.

Kücklich, J. 2005. "Precarious playbour: Modders in the digital games industry', Fibreculture" 5 [http://journal.fibrec ulture.org/issue5/index.html].

Millington, B. 2016. "Fit for Prosumption: Interactivity and the Second Fitness Boom" [http://mcs.sagepub.com/content/early/2016/04/20/0163443716643150

Ritzer, G. and Jurgenson, N. 2010. "Production, Consumption, Prosumption: The nature of capitalism in the age of the digital 'prosumer'." Journal of Consumer Culture. 10 (1): 13-36. Roberts, K. 2006. Leisure in Contemporary Society. Wallingford: CABI.

Rojek, C. 1993. Ways of Escape: Modern Transformation in Tourism and Travel.

Buckingham: Palgrave Macmillan.

Veblen, T. 1925/1899. The Theory of the Leisure Class: An Economic Study of Institutions. London: Allen and Unwin.

Willis, S. 1991. A Primer for Daily Life. London: Routledge. 
Woermann, N. 2011. "Subcultures of Prosumption" - Prosumption as distinction in freeskiing". European Advances in Consumer Research. Volume 9, eds. A. Bradshaw, C. Hackley, and P. Maclaran. Duluth, MN : Association for Consumer Research: 627-628. 